\title{
EL REPOSITORIO EN ESPAÑOL DE RADIO FRANCIA INTERNACIONAL: LA AUDIENCIA DE LATINOAMÉRICA Y ESPAÑA COMO OBJETIVO ESTRATÉGICO
}

\section{THE SPANISH-LANGUAGE REPOSITORY OF RADIO FRANCE INTERNATIONAL: THE AUDIENCE OF LATIN AMERICA AND SPAIN AS A STRATEGIC OBJECTIVE}

\section{Juan Carlos González Pérez. Universidad Complutense de Madrid. España.}

Giguel Ángel Ortiz Sobrino. Universidad Complutense de Madrid. España.

GAna Mancho Laiglesia. Universidad de Zaragoza. España.

Gacinto Gómez López. Universidad Complutense de Madrid. España.

\section{Cómo citar el artículo:}

González Pérez, J. C., Ortiz Sobrino, M. A., Mancho Laiglesia, A. y Gómez López, J. (2021). El repositorio en español de Radio Francia Internacional: la audiencia de Latinoamérica y España como objetivo estratégico. Revista de Ciencias de la Comunicación e Información, 26, 27-44.

http://doi.org/10.35742/rcci.2021.26.e119

\section{RESUMEN}

Este artículo es el resultado de un análisis de la oferta de contenidos en español a través de la Radio France International. En él se ofrece una sistematización y clasificación de sus programas en la web en la que se toman como puntos de referencias el nombre del programa, su contenido, su temática y el modelo de producción. De los 21 programas de la parrilla de la emisora en español de RFI, ocho son de temática informativa, la principal en sus contenidos. El objetivo de estos programas es acercar la cultura francesa a los hispanoparlantes, así como descubrir las similitudes de talento que pueden existir con esa cultura de España y Latinoamérica. Además, la fonoteca de la radio pública internacional de Francia permite al oyente viajar por temas de actualidad general o cultural: cine, danza, música, teatro o literatura.

Palabras clave: Radio France International, radiodifusión exterior, radio pública francesa, web RFI, radio web internacional. 


\begin{abstract}
This article is the result of an analysis of the content offer in Spanish through Radio France International. It offers a systematization and classification of its programs on the web, taking as reference points the name of the program, its content, its theme and the production model. Of the 21 programs that the Spanish radio station RFI broadcasts on its grid, eight are informative, the main one in terms of content. The objective of these programs is to bring French culture closer to Spanish speakers, as well as to discover the similarities of talent that may exist with that culture in Spain and Latin America. In addition, the sound library of the International Public Radio of France allows the listener to travel through general or cultural current affairs: film, dance, music, theater or literature.
\end{abstract}

Keywords: Radio France International, external radio broadcasting, French public radio, web $\mathrm{RFI}$, international cyber radio.

\title{
1. INTRODUCCIÓN
}

En 1927 la BBC, emisora pública del Reino Unido comenzó a emitiré programas para sus colonias distribuidas por el mundo. El 19 de diciembre de 1932 inauguró el servicio de emisión de veinticuatro horas al día con destino a los territorios británicos en África, India, Australia y Canadá. Fue la primera experiencia en serio de los que luego vendría a denominarse el servicio público exterior de radiodifusión en la mayoría de los países de la vieja Europa. Esta experiencia británica comenzó a tener sus réplicas en las radios públicas de otros países europeos: en unos casos, por ejemplo, en España, concebida en un primer momento como un arma de propaganda y, en otros, como medio de mantener en contacto a la Nación con los ciudadanos del país que residían en el extranjero.

Pero la misión de las radios públicas internacionales ha ido transformándose. En este sentido, una de las misiones importantes de los servicios de radiodifusión internacional de los estados democráticos actuales reside en proyectar la imagen de un país y su visión del mundo.

Internet ha venido a facilitar las cosas y a romper las barreras de acceso e interacción con la radio en las diferentes zonas partes del mundo. La producción de contenidos es mucho más barata y el mundo está al alcance de un clic. No es extraño entonces que este tipo de emisoras hayan potenciado sus servicios en internet para conseguir sus objetivos. Así lo ha hecho radio Francia Internacional.

\subsection{Marco contextual: contexto histórico y fundacional.}

En los últimos años del pasado siglo, comentaba Ortega Benito (1997) que Radio France International (RFI) es una de las sociedades nacionales de programas del sector público del sector audiovisual francés.

Creada por ley el 29 de julio de 1986 como sociedad filial de Radio France, se le concedió el estatus de sociedad autónoma por la ley 3986, del 30 de septiembre, relativa a la libertad de comunicación. El Consejo de Administración de la RFI está 
formado por representantes del Parlamento, representantes del personal del Estado y de personalidades designadas por la Comisión Nacional de la Comunicación y de las Libertades.

Como el resto de las emisoras públicas internacionales europeas, RFI está encargada de la transmisión de emisiones de radiodifusión sonora destinadas a la difusión internacional, como sucede por ejemplo en España (Ortiz Sobrino, 2013). Sostiene Ortiz Sobrino que, en el caso español, Radio Exterior de España se ha afianzado como vehículo de proyección de la imagen de España en el extranjero. Hasta tal punto que, en los primeros años de la primera década del milenio, se contabilizaban emisiones en diez idiomas diferentes: español, inglés, francés, alemán, árabe, ruso, catalán, vasco, gallego y sefardí: idiomas que tienen un valor estratégico y comercial para el Estado español. Lo mismo ocurre en Radio Francia Internacional, que en los últimos años ha venido realizando emisiones en idiomas como el árabe, el camboyano, el chino, el español, el inglés, el portugués, el rumano o el ruso. En esta clave de interés estratégico para Francia deben enmarcarse sus emisiones en español y su colaboración como difusores de estos contenidos con emisoras del Tercer sector (Ortiz Sobrino,2014), como también sucede en el caso español don ha sido destacada su labor de cooperación internacional, llevada a cabo a través de convenios con más de seiscientas emisoras en español repartidas por todo el mundo (Calvo, 2006).

Radio Francia Internacional es una emisora internacional pública francesa. Su sede se encuentra en París. RFI produce programas en francés y 13 idiomas más, árabe, camboyano, chino, hausa, inglés, suajili, persa, portugués, rumano, ruso y vietnamita. Una de sus emisoras más destacadas es la correspondiente al idioma español, ya que abarca la audiencia de España y de países latinoamericanos.

La literatura científica se ha hecho eco de las características y la perspectiva histórica del servicio exterior de radiodifusión, tanto en Francia como en España. En el caso español, cabe citar las aportaciones de Martínez Arias y Martínez Arias (2013), Ortiz Sobrino (2014), Martin Caro (2000) Calvo 2006 o Montes Fernández 2018. En el caso de Francia, destacan la obra de Glevarec (2012), la de Hendrick (2011), la de Lefebvre (2011), la Cheval (1997, 2003, 2008 y 2010) y las contribuciones promovidas por el Groupe de Recherches et d'Études sur la Radio, que permiten enmarcar la radio pública internacional francesa, tanto en sus orígenes como a partir de la gran reforma llevada a cabo tras la entrada en vigor de reforma Mitterrand en aquel país, en $1981 / 1982$.

\subsection{Radio Francia Internacional en el contexto de la radio en Internet.}

Según Milito y Cajús (2009) Internet ha abierto nuevas posibilidades para la radio, tanto para la distribución de la señal como para la incorporación de las redes sociales. Comentan los autores que la presencia de la radio en Internet abre el camino a una forma distinta de hacer radio y empaquetar los contenidos en formato podcast (Gallego-Pérez (2010 y 2012) y Ortiz Sobrino (2012), entre otros.

La radio adquiere con Internet una cobertura y alcance internacional. De esta manera, abre a la radio la posibilidad de transnacionalización y globalización de sus 
contenidos. Aprovechar estas nuevas posibilidades es lo que viene haciendo la radio pública internacional francesa.

Comenta Cea-Esteruelas (2016) que internet es ampliamente utilizado por las emisoras líderes en audiencia en España, Francia, Reino Unido y Alemania. Con respecto al modelo de distribución, se detecta una importante evolución con respecto a estudios previos, ya que el uso del webcast y el podcast prácticamente ya se ha generalizado. Los datos arrojados por uno de sus estudios reflejan que la totalidad de las radios líderes en audiencia en esos cuatro países difunden los contenidos sonoros y radiofónicos a través de Internet en directo (simulcast).

Martínez Costa, Moreno y Amoedo (2018), dan cuenta de la presencia la importancia de internet para las emisiones de radio en la actualidad. En ese sentido, se refieren a la amplia bibliografía sobre la radio online abordada desde diferentes ópticas: desde la fundamentación teórica - Cebrián-Herreros (2008 y 2009), Martínez-Costa; Moreno; Amoedo-, a la fundamentación empírica - González Conde (2014), Gallego-Pérez, (2010 y 2012) y Cea-Esteruelas, (2016).

Radio Francia Internacional difunde su señal a través de satélites, su sitio web en Internet y aplicaciones para teléfonos móviles. En 1996, el presidente de RFI, JeanPaul Cluzel, transforme RFI en una radio de información continua, 24 horas al día, a escala mundial en 17 idiomas además del francés. Ese mismo año se crea su sitio web, y en 1998 su par en español. Los sistemas utilizados son el streaming o el podcast, principalmente.

En los últimos años, Radio Francia Internacional, ha venido realizando emisiones en idiomas como el árabe, el chino, el español, el inglés, el portugués, el rumano o el ruso. En esta clave de interés estratégico para Francia deben enmarcarse sus emisiones en español y su colaboración como difusores de estos contenidos con emisoras del Tercer sector, como también sucede en el caso español.

\section{OBJETIVOS}

El objetivo de esta investigación se ha centrado en el análisis de la oferta de contenidos en español de Radio Francia Internacional, a través de la web, independientemente de que se trate de una producción propia o asociada con otras instituciones.

De igual medida, se ha pretendido contextualizar esta oferta en relación con otras actividades de la emisora, en relación con la cooperación internacional

\section{METODOLOGÍA}

Tras una contextualización histórico-tecnológica que ha exigido retomar algunas contribuciones de la literatura científica, se ha procedido al análisis del repositorio de programas en español ofrecido por RFI.

La metodología utilizada se ha basado en el análisis de los contenidos de los programas que posee Radio Francia Internacional en su página web. 
A partir de ahí se ha procedido a sistematizar y clasificar los contenidos de los programas ofertados por la emisora a través de internet. En este sentido, se ha procedido a elaborar una estructura de clasificación basada en cuatro ítems: nombre del programa, contenido, temática y origen de la producción. Se han identificado veintiún programas distintos, de temáticas y duración variadas, que han sido escuchados y clasificados según los ítems referenciados.

El trabajo de análisis se realizó entre los meses de septiembre y diciembre de 2019.

\section{DISCUSIÓN / RESULTADOS}

Radio France Internacional en internet: repositorio de programas en la web.

\subsection{Análisis de la página web y del impacto del español.}

Radio France Internacional arrancó en 1998 su página web específica de contenidos en español. El enlace es una derivación de la página web oficial, de ahí la relevancia que tiene para Radio France la presencia en español. http://www.rfi.fr/es/

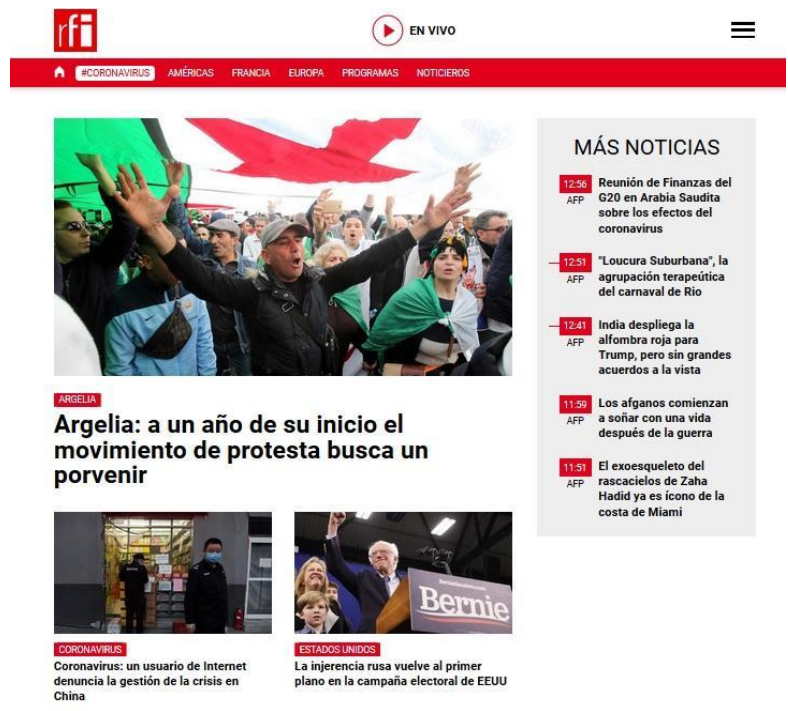

Figura 1. Portal web de RFI en español Fuente: http://www.rfi.fr/es/

La página web tiene un papel eminentemente informativo, ya que desde un primer momento se aprecia que es una ventana informativa, visual e intuitiva marcada por las noticias que aparecen en primer término y el repositorio de "Más noticias" en el apartado derecho. 


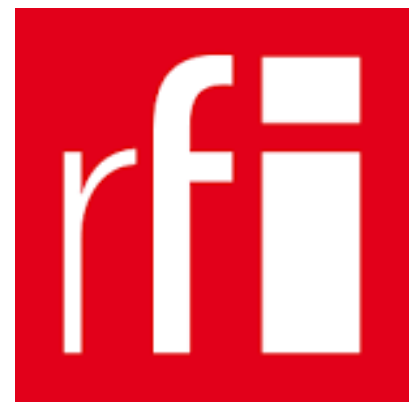

Figura 2. Logo de RFI

Fuente: http://www.rfi.fr/es/

En el menú desplegable (Foto 3), Radio Francia Internacional divide sus contenidos en Actualidad y Escuchar, en la línea de ofrecer información y contenidos radiofónicos en español. En el apartado Actualidad se aprecian ya los contenidos y su línea temática, centrados en información e internacionalización, así como contenidos culturales, económicos, sociales y deportivos. En el apartado de Actualidad además queda claro que el público principal al que se enfoca la programación de RFI en español es el público de América, que es la primera categoría en el menú de portada. A partir de ahí, también se producen y difunden contenidos de Francia, Europa, África, Oriente Medio y Asia Pacífico.

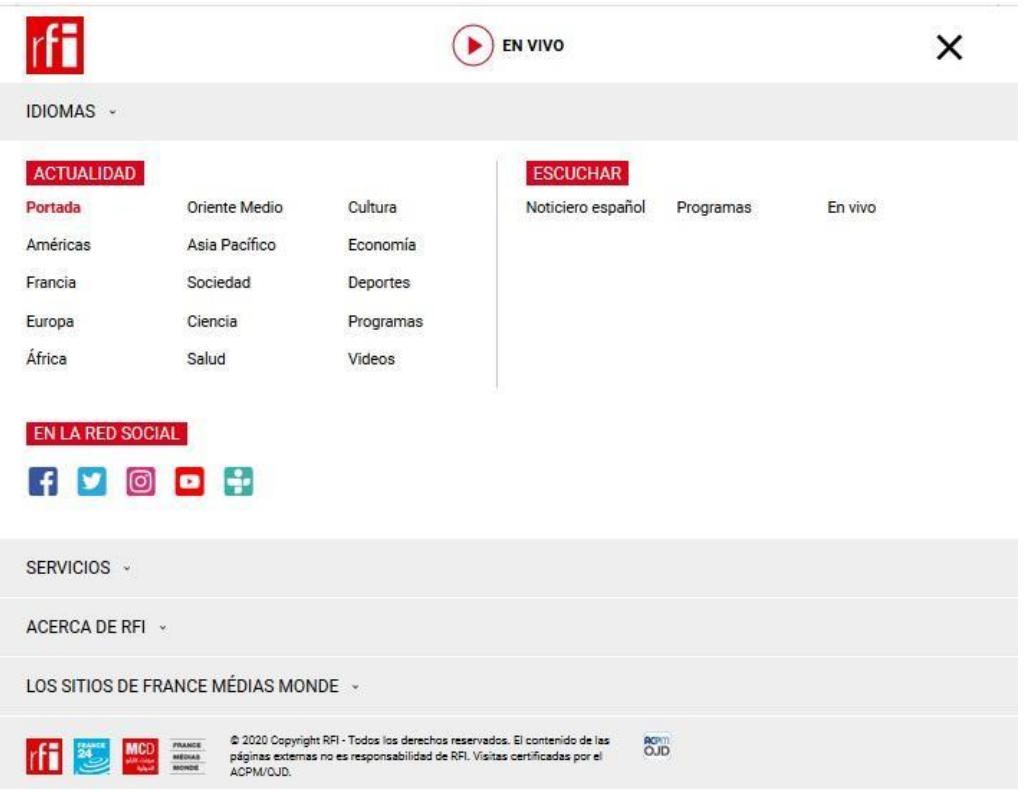

Figura 3. Menú desplegable dentro del portal web de RFI Internacional en español

Fuente: http://www.rfi.fr/es/

La presencia radiofónica en la sección "Escuchar" es también muy relevante, junto a la presencia informativa. El visitante encuentra la opción de escuchar "En vivo" la emisora en la parte superior del menú principal. Además, los contenidos radiofónicos aparecen en numerosos apartados de la página inicial y subpáginas.

RFI difunde su señal a través de satélites, su sitio web en Internet (streaming y podcasts) y aplicaciones para teléfonos móviles. La señal está disponible en varias 
empresas de televisión por suscripción. En algunos países, RFI tiene acuerdos con emisoras FM para la retransmisión de sus programas.

Además, las redes sociales y la emisión a través de YouTube y de Tune In tienen una fuerte presencia en la portada. Radio Francia Internacional posee perfiles en medios sociales específicos para su emisora en español y ofrece al oyente la posibilidad de escuchar sus programas en directo y en diferido no solo en la página web sino a través de dispositivos móviles o altavoces inteligentes mediante la aplicación Tune In, donde la emisora ya tiene más de 10 mil seguidores. Tune In es ya una de las principales apps para escuchar radio en streaming en todo el mundo.

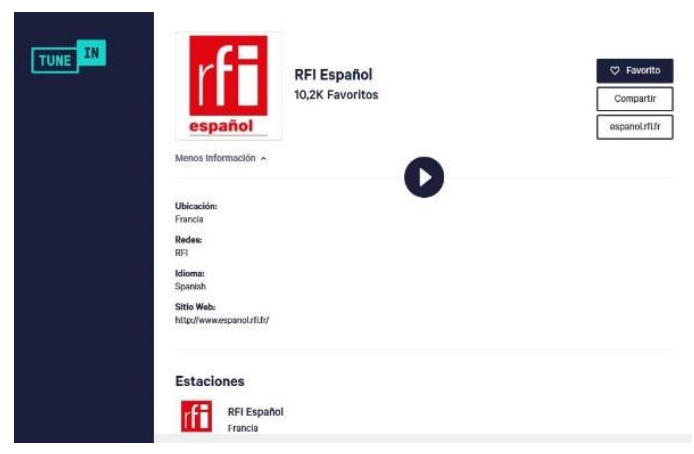

Figura 4. Perfil oficial de RFI español en la app de streaming radiofónico Fuente: Tune In.

En la página principal, los contenidos destacados aparecen con una \# en portada, seguidos de las localizaciones más destacadas y de un acceso directo al directorio de programas y a los noticieros. En el apartado de Noticieros, puede escucharse de forma fragmentada el último noticiero emitido para facilitar al oyente la identificación de contenidos y ofrecer fragmentos más cortos (De no más de 20 minutos de duración).

\subsection{Análisis de la parrilla radiofónica y relevancia.}

Según datos recogidos en la página web de France Medias Monde, "Sus colaboradores son de 66 nacionalidades diferentes. Cada semana, RFI, France 24 y Monte Carlo Doualiya llegan 173 millones de contactos (45\% de ellos en idiomas distintos al francés), incluidos 126,9 oyentes y telespectadores (medición realizada en 65 países de los 183 en los que se emite al menos una de las cadenas) y 46,3 millones de visitas mensuales en sus universos digitales (promedio de 2018). En diciembre de 2018, los abonados en Facebook y Twitter llegaban a los 65 millones. France Médias Monde es la empresa matriz de CFI, la agencia francesa de cooperación para los medios, y es uno de los accionistas de la cadena francófona TV5MONDE."

Los programas de RFI tienen un origen mayoritariamente francés, pero varios contenidos se producen desde las corresponsalías de RFI en países latinoamericanos. Los locutores tienen una variedad amplia de acentos y los presentadores son locutores anónimos, personas de la sociedad civil, profesionales de RFI o periodistas hispanoamericanos, como es el caso del periodista argentino afincado en París, Alejo Schapire, que presenta el programa algo que decir. 
La mayoría de los programas son producción propia de RFI, aunque la colaboración con otras instituciones y medios como France24 o Monte Carlo Doualiy queda patente en los créditos de la página web. En definitiva, estos medios, junto a RFI forman el grupo France Médias Monde, empresa del Estado francés.

Profundizando en los programas que produce RFI en español, y que están unificados en el apartado Programas (llustraciones 5 y 6 ) de la portada, identificamos 21 programas distintos de temáticas y duración variadas.

Repositorio en español

Radio France Internacional

- Número de programas

$\square \quad 21$ programas

- $\quad$ Nombre de los programas

$\square \quad$ Algo que decir

$\square \quad$ Carrusel de las artes

$\square \quad$ Crónica cultural

$\square \quad$ Crónicas Deportivas

$\square \quad$ Curso de francés: ¿Parlez vous Paris?

$\square \quad$ Economía y finanzas

$\square \quad$ El deportivo de RFI

$\square \quad$ El invitado de RFI

$\square \quad$ Enfoque Internacional

$\square \quad$ En Primera Plana

$\square \quad$ Escala en París

$\square \quad$ Francés de todos

$\square \quad$ Francia Hoy

$\square \quad$ Grandes reportajes de RFI

$\square \quad$ La fonoteca de RFI

$\square \quad$ Mundo ciencia
Noticias de América

$\square \quad$ París América

$\square \quad$ Programas especiales

$\square \quad$ Salud y Bienestar

$\square \quad$ Vida en el planeta

- $\quad$ Temática de los programas

$\square \quad$ Información

$\square \quad$ Entrevistas

$\square \quad$ Economía

$\square \quad$ Cultura

$\square \quad$ Deportes

$\square \quad$ Ciencia

$\square \quad$ Medio ambiente

- Educación

- $\quad$ Origen de los programas

$\square \quad$ Producción RFI

$\square \quad$ Coproducción RFI y emisoras

$\square \quad$ RFI y France 24 en español 
EL REPOSITORIO EN ESPAÑOL DE RADIO FRANCIA INTERNACIONAL: LA AUDIENCIA DE LATINOAMÉRICA Y ESPAÑA COMO OBJETIVO ESTRATÉGICO

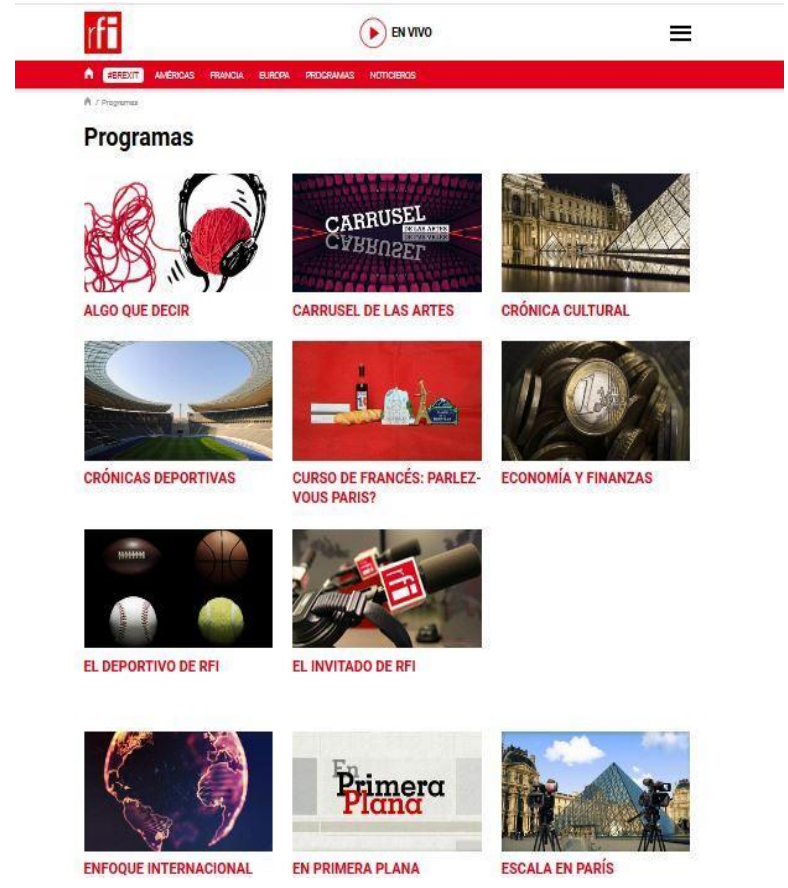

Figura 5. Repositorio de programas de RFI en español Fuente: http://www.rfi.fr/es/

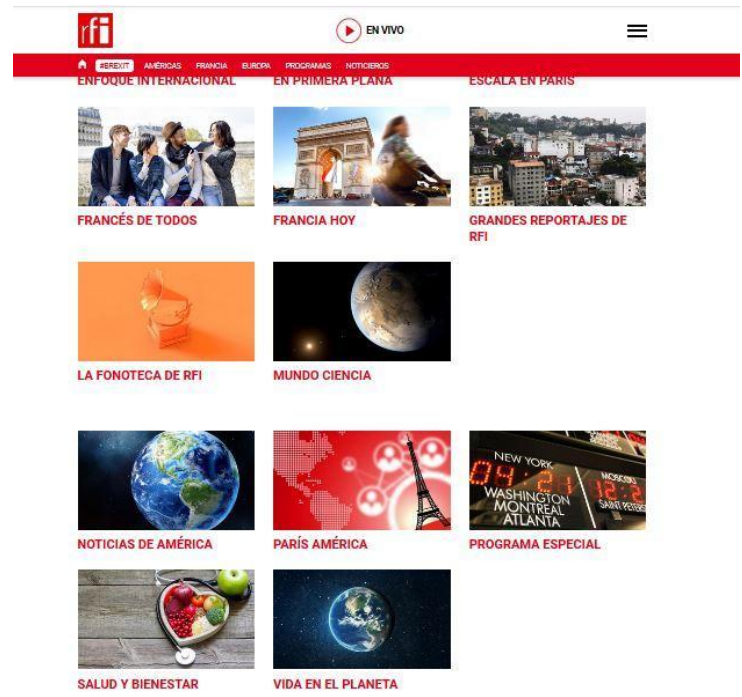

Figura 6. Repositorio de programas de RFI en español Fuente: http://www.rfi.fr/es/ 
Tabla 1. Descripción de contenidos de los programas en español.

\begin{tabular}{|c|c|c|c|}
\hline Nombre & Contenido & Temática & $\begin{array}{l}\text { Origen de los } \\
\text { programas }\end{array}$ \\
\hline Algo que decir & $\begin{array}{l}\text { Una conversación } \\
\text { entrevista con perfiles } \\
\text { internacionales de cara a } \\
\text { profundizar } \\
\begin{array}{l}\text { opiniones sobre temas, } \\
\text { globales }\end{array}\end{array}$ & Información & Producción RFI \\
\hline Carrusel de las artes & $\begin{array}{l}\text { Reportaje semanal de } \\
\text { temática cultural sobre } \\
\text { música, literatura, cine, } \\
\text { artes escénicas, danza, } \\
\text { fotografía, francesa y } \\
\text { latinoamericana }\end{array}$ & Cultura & Producción RFI \\
\hline Crónica cultural & $\begin{array}{lcc}\text { Programa } & \text { sobre } & \text { la } \\
\text { actualidad } & \text { cultural } & \text { en } \\
\text { Francia } & & \end{array}$ & Cultura & Producción RFI \\
\hline Crónicas Deportivas & $\begin{array}{l}\text { Programa de actualidad } \\
\text { deportiva sobre eventos } \\
\text { recientes con conexiones } \\
\text { internacionales }\end{array}$ & Deporte & Producción RFI \\
\hline $\begin{array}{l}\text { Curso de francés: Parlez } \\
\text { vous Paris? }\end{array}$ & $\begin{array}{l}26 \text { reportajes bilingües } \\
\text { hechos por extranjeros } \\
\text { para conocer París y } \\
\text { practicar el idioma en la } \\
\text { ciudad }\end{array}$ & Educación & Producción RFI \\
\hline Economía y finanzas & $\begin{array}{l}\text { Magazine dedicado a los } \\
\text { temas económicos que } \\
\text { protagonizan la actualidad } \\
\text { francesa, latinoamericana y } \\
\text { mundial con análisis de } \\
\text { expertos }\end{array}$ & Economía & Producción RFI \\
\hline El deportivo de RFI & $\begin{array}{l}\text { Resumen deportivo de la } \\
\text { semana, con fútbol, tenis, } \\
\text { ciclismo, rugby, Fórmula } 1 \\
\text { + crónicas internacionales }\end{array}$ & Deporte & Producción RFI \\
\hline El invitado de $R F I$ & $\begin{array}{l}\text { Entrevista a un invitado en } \\
\text { el estudio para tratar temas } \\
\text { sobre actualidad política o } \\
\text { cultural }\end{array}$ & Información & Producción RFI \\
\hline Enfoque Internacional & $\begin{array}{l}\text { Programa de análisis de un } \\
\text { tema de la actualidad } \\
\text { mundial para analizarlo en } \\
\text { profundidad, con } \\
\text { entrevistas a expertos y } \\
\text { actores del sector político y } \\
\text { social }\end{array}$ & Información & Producción RFI \\
\hline
\end{tabular}




\section{EL REPOSITORIO EN ESPAÑOL DE RADIO FRANCIA INTERNACIONAL: LA AUDIENCIA DE LATINOAMÉRICA Y ESPAÑA COMO OBJETIVO ESTRATÉGICO}

\begin{tabular}{|c|c|c|c|}
\hline En Primera Plana & $\begin{array}{l}\text { Corresponsales de la } \\
\text { prensa extranjera en París } \\
\text { y expertos analizan cada } \\
\text { semana lo más destacado } \\
\text { de la actualidad. }\end{array}$ & Información & $\begin{array}{l}\text { Coproducción RFI y } \\
\text { France } 24 \text { en español }\end{array}$ \\
\hline Escala en París & $\begin{array}{l}\text { Coproducida con France } 24 \\
\text { en español, Escala en París } \\
\text { es una cita semanal con } \\
\text { artistas, deportistas, } \\
\text { empresarios, científicos, } \\
\text { protagonistas de la política, } \\
\text { etc. Un puente entre } \\
\text { América latina y la Ciudad } \\
\text { Luz. }\end{array}$ & Entrevistas & $\begin{array}{l}\text { Coproducción RFI y } \\
\text { France } 24 \text { en español }\end{array}$ \\
\hline Francés de todos & $\begin{array}{l}\text { Programa que ayuda a los } \\
\text { no francófonos a diferenciar } \\
\text { sobre los distintos tipos de } \\
\text { acentos que existen en el } \\
\text { idioma para entender, por } \\
\text { ejemplo, el este francés de } \\
\text { la calle o cotidiano. }\end{array}$ & Educación & Producción RFI \\
\hline Francia Hoy & $\begin{array}{l}\text { Magacín semanal "que } \\
\text { aborda temas de sociedad } \\
\text { o política francesa, } \\
\text { profundizando en cada uno } \\
\text { de ellos con el análisis de } \\
\text { expertos y testimonios. }\end{array}$ & Información & Producción RFI \\
\hline Grandes reportajes de RFI & $\begin{array}{l}\text { Programa realizado por los } \\
\text { reporteros de RFI alrededor } \\
\text { del mundo, que permite, } \\
\text { detrás de las noticias, } \\
\text { explorar un tema, un lugar, } \\
\text { una problemática. }\end{array}$ & Información & Producción RFI \\
\hline La fonoteca de RFI & $\begin{array}{l}\text { Programa que explora la } \\
\text { música francesa } \\
\text { internacional }\end{array}$ & Cultura & Producción RFI \\
\hline Mundo ciencia & $\begin{array}{l}\text { Programa que aborda } \\
\text { temas científicos, ciencia, } \\
\text { desde la arqueología hasta } \\
\text { el espacio sideral. }\end{array}$ & Ciencia & Producción RFI \\
\hline Noticias de América & $\begin{array}{l}\text { Programa informativo que } \\
\text { analiza la actualidad } \\
\text { latinoamericana con las } \\
\text { voces de protagonistas y } \\
\text { observadores de la región. }\end{array}$ & Información & Producción RFI \\
\hline París América & $\begin{array}{l}\text { Programa interactivo de } \\
\text { RFI, sus radios asociadas y } \\
\text { los oyentes }\end{array}$ & Información & $\begin{array}{l}\text { Producción RFI, } \\
\text { radios asociadas y } \\
\text { participación } \\
\text { ciudadana a través } \\
\text { de WhatsApp y email. }\end{array}$ \\
\hline
\end{tabular}


Juan Carlos González Pérez, Miguel Ángel Ortiz Sobrino, Ana Mancho Laiglesia y Jacinto Gómez López

\begin{tabular}{|l|l|l|l|}
\hline Programa especial & $\begin{array}{l}\text { Programas especiales de } \\
\text { gran formato y } \\
\text { monotemáticos sobre un } \\
\text { acontecimiento de gran } \\
\text { envergadura }\end{array}$ & $\begin{array}{l}\text { Redacción } \\
\text { profesionales de RFI } \\
\text { y producción RFI }\end{array}$ \\
\hline Salud y Bienestar & $\begin{array}{l}\text { Magacín semanal dedicado } \\
\text { a los temas de salud y } \\
\text { calidad de vida. }\end{array}$ & Sociedad & Producción RFI \\
\hline Vida en el planeta & $\begin{array}{l}\text { Programa dedicado a a deta, planeta, } \\
\text { temas del ambiente } \\
\text { especialmente temática de } \\
\text { concienciación medio } \\
\text { ambiental. }\end{array}$ & Producción RFI \\
\hline
\end{tabular}

Fuente: Elaboración propia.

De los 21 programas que emite en su parrilla la emisora en español de RFI, ocho son de temática informativa, la principal en sus contenidos. No es de extrañar, pues RFI forma parte del conglomerado de medios informativos que ya comentamos previamente y tiene una función eminentemente de actualidad que queda reflejada en su slogan: "Noticias del mundo en directo". Dentro del género informativo, se mezclan boletines de gran formato con entrevistas.

El programa estrella es precisamente el Noticiero diario que se complementa con programas como Noticias de América (que profundiza en la actualidad de Latinoamérica mediante voces de expertos y protagonistas) o Algo que decir, programa de entrevistas. El carácter internacional y la fortaleza del grueso de corresponsales que posee RFI, se enmarca en el programa Enfoque Internacional pero especialmente en el espacio En primera plana, que consiste en una ronda de corresponsales por todos los rincones donde RFI y France 24 se encuentran presentes.

Tras la temática informativa, los contenidos culturales son el otro pilar de la programación en español de RFI. El objetivo es acercar la cultura francesa a los hispanoparlantes, así como descubrir las similitudes de talento que pueden existir con esa cultura de España y Latinoamérica. Carrusel de las artes, Crónica cultural y La fonoteca de RFI (llustración 7) permiten al oyente viajar por temas de actualidad y de no tanta actualidad cultural, desde el cine a la danza, pasando por la música, el teatro o la literatura. Mención especial tiene el espacio la Fonoteca de RFI, que ejerce semanalmente de contenedor radiofónico de música francesa, contrastando con la información que copa gran parte de la programación de la emisora. 


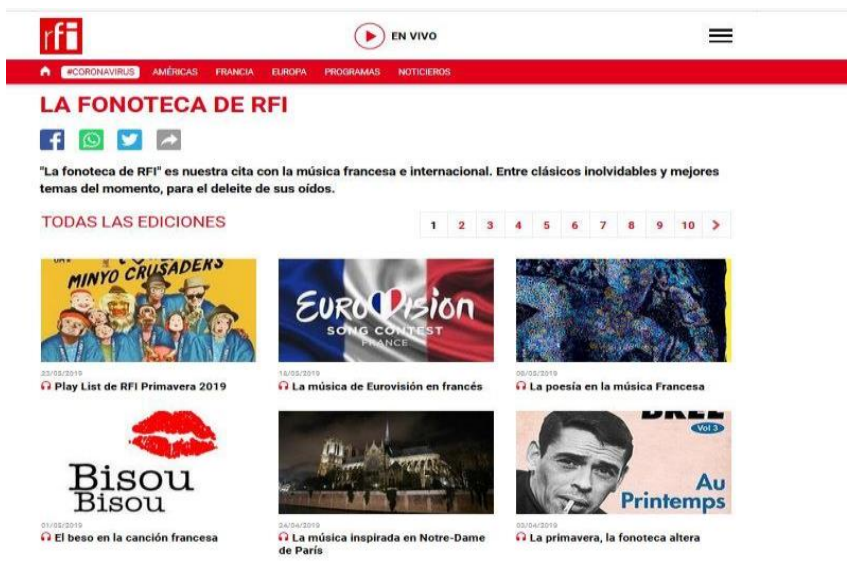

Figura 7. Espacios musicales del programa "La fonoteca de RFI"

Fuente: http://www.rfi.fr/es/

RFI en español también tiene programas de Deportes, Sociedad, Ciencia, Medio Ambiente o Programas Especiales.

En todos ellos, la emisora potencia la fortaleza de su amplia red de corresponsales y profesionales por todo el mundo. Es el caso especial del programa Crónicas Deportivas en el que se realizan conexiones internacionales para conocer los resultados de deportes tan variados como el fútbol, el tenis o el rugby así como las historias detrás de sus protagonistas. En el plano social, los temas de salud, bienestar, calidad de vida y medio ambiente que preocupan cada vez más a la población mundial y por ende a los oyentes de radio, tienen cabida en espacios como Salud y Bienestar o Reportajes claros y fáciles de entender con participación de expertos que resuelven dudas y aclaran conceptos que atañen a la sociedad. La duración de dichos espacios es breve y directa, entre 15 y 30 minutos, y en numerosas ocasiones tienen una estructura muy didáctica, como el dedicado a la enfermedad Alzheimer: 9 factores de riesgo modificables.

Los temas informativos pueden dar lugar a un gran tema de carácter global que merece ser abordado de forma profunda y a través de distintos enfoques. El espacio "Programa especial" es el gran contenedor en el que trabajan de forma más coordinada todos los profesionales de las redacciones de RFI.

Programas especiales de gran formato y monotemáticos sobre un acontecimiento de gran envergadura de temas recientes como el Brexit, el incendio de Notre-Dame o la lucha por la igualdad y el movimiento MeToo.

Una de las áreas informativas más relevantes en la programación de RFI es la Economía. La visión global de los temas económicos mediante píldoras informativas y espacios de no más de 30 minutos incluye análisis y entrevistas a expertos de todos los continentes.

El carácter público y social de RFI se percibe también en los contenidos educativos, especialmente enfocados en hacer pedagogía del idioma francés en aquellos que no lo dominan, pero quieren aprenderlo o se encuentran en proceso de ello. El objetivo es facilitar al oyente hispanoparlante de cualquier parte del mundo, mediante los 
podcasts o en directo una herramienta didáctica para aprender de forma fácil, sencilla, cómoda y accesible el idioma francés. El espacio Parlez vous Paris? consiste en 26 reportajes bilingües hechos por extranjeros para conocer París y practicar el idioma desde la propia ciudad consiguiendo difundir de forma pedagogía el francés y además ofrecer contenidos turísticos y culturales. Si los alumnos / oyentes de radio ya tienen un dominio del idioma, existe el espacio radiofónico Francés de todos, en el que RFI permite descubrir los acentos y distintas formas de utilizar el idioma.

Aunque los programas de RFI tienen un origen de producción mayoritariamente francés, hay que destacar que los locutores tienen una variedad amplia de acentos y los presentadores son locutores anónimos, personas de la sociedad civil, profesionales de RFI o periodistas hispanoamericanos. Este hecho no es casual porque, seguramente, Radio Francia Internacional quiere ser respetuoso con la diversidad de acentos que representan la lengua y la cultura de Hispanoamérica y España.

En una radio online, la interacción es esencial. Precisamente, ese carácter participativo es uno de los ejes de RFI, con su programa destinado al público Latinoamericano, París América. Este espacio, producido en conjunto por RFI y sus radios asociadas se da paso a la participación ciudadana desde ambos continentes americano y europeo, mediante mensajes de voz y mails. sus mensajes de voz, llamadas o email. El resultado es un programa muy cercano al oyente, con temas que le interesan y que ellos mismos configuran. Desde problemáticas en comunidades indígenas, pasando por talentos culturales por descubrir o emprendimiento ciudadano. Los temas son muy variados, como un contenedor social, y son coordinados y conducidos por profesionales de RFI y de sus emisoras asociadas.

\subsection{Convenio con otras emisoras, programas especiales y premios.}

A lo largo de sus más de 20 años de vida, Radio Francia Internacional ha realizado colaboraciones con emisoras de España y Latinoamérica para emitir sus programas en dichas cadenas o realizar sinergias entre ondas.

En las Rutas Cervantes del Instituto Cervantes de París, se recordó los años de radio del escritor y Premio Nobel de Literatura, Mario Vargas Llosa en RTF (emisora previa a RFI):

Durante los siete años que Mario Vargas Llosa vivió en París, el escritor trabajó la mayor parte de ellos en los programas radiofónicos en español de la extinta Radio Televisión francesa, la RTF, que hoy se emiten a través de Radio Francia Internacional (RFI). En la radio tuvo un programa llamado "la literatura en debate" en el que entrevistó a escritores como Pablo Neruda, Jorge Luis Borges y Ernesto Sábato, entre otros. Vargas Llosa trabajó durante varios años en este edificio, desde su inauguración en 1963.

Por su parte, en 2005 con ocasión de la Cumbre Euro mediterránea que acogió Barcelona, Catalunya Ràdio y Radio France Internationale (RFI) firmaron un convenio para emitir un programa radiofónico conjunto que se emitió coincidiendo con los actos 
de dicha cumbre por la frecuencia que Radio France Internacional tiene en Barcelona en el 105.3 de la FM,

Un total de seis programas de media hora, de contenido cultural y europeo en catalán, que permitieron a Catalunya Radio "colaborar con una de las principales radios transnacionales que hay en el mundo" y poner las bases para "futuros proyectos", en palabras del director de la emisora en aquella época, Oleguer Sarsanedas.

La apuesta de RFI Internacional por el periodismo de calidad, la sinergia entre talento francés e hispanoamericano queda patente en la entrega del premio "Reportaje RFI en español" (llustración 8) que en 2019 celebró su quinta edición. Un galardón destinado a estudiantes de periodismo menores de 30 años, residentes en América Latina y el Caribe. Para participar, los estudiantes deben enviar un reportaje radiofónico de una duración máxima de 13 minutos, así como una propuesta de reportaje para realizar en París, que finalmente podrá realizarse durante los cuatro meses de estancia totalmente pagada que obtiene el ganador del certamen.

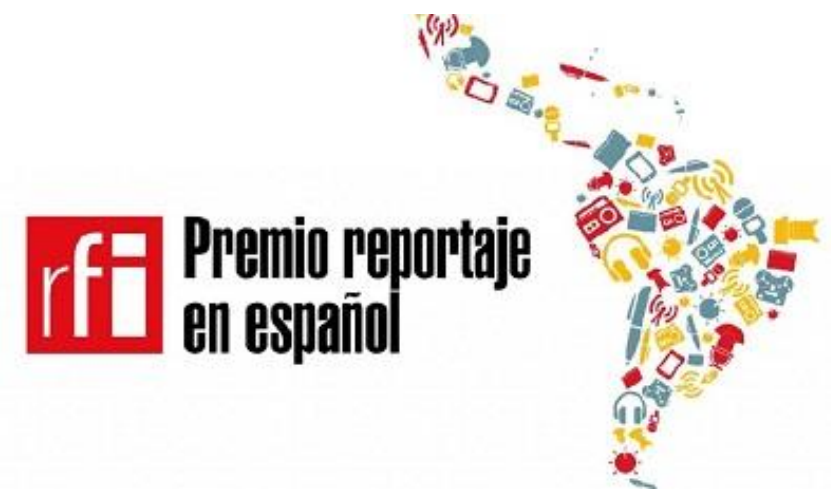

Figura 8. Logotipo del Premio Reportaje en español que entrega RFI

Fuente: http://www.rfi.fr/es/

\section{CONCLUSIONES}

Como el resto de las emisoras públicas internacionales europeas, Radio Francia Internacional tiene encomendado la emisión de contenidos dirigidos a otros países está encargada de la transmisión de emisiones de radiodifusión sonora destinadas a la difusión internacional, como sucede con el resto de las principales radios públicas europeas, entre ellas Radio Exterior de España. El objetivo de estos programas es acercar la cultura francesa a la población de habla hispana en lberoamérica y España.

La página web tiene un papel eminentemente informativo, ya que desde un primer momento se aprecia que es una ventana informativa, visual e intuitiva marcada por las noticias. De hecho, del análisis de los veintiún programas que se emiten en la parrilla de la emisora en español, ocho son de temática informativa.

El carácter educativo de Radio France International se refleja en contenidos de divulgación del idioma francés en los que, además, participan locutores con una variedad amplia de acentos y de orígenes, en programadas destacados como Parlez vous Paris? 
Este hecho no es casual porque Radio France Internacional quiere ser respetuoso con la diversidad de acentos que representan la lengua y la cultura de Hispanoamérica y España.

En definitiva, este servicio exterior de la radio pública francesa se enmarca en el papel de este tipo de radios europeas, en el que las radios internacionales trasladan, desde la perspectiva del país emisor, su visión de los diferentes aspectos informativos de carácter mundial.

\section{REFERENCIAS}

Cea-Esteruelas, N. (2016). Modelo comunicativo de la radio web: estudio de las principales emisoras europeas. Estudios sobre el mensaje periodístico, 22(2), 953968. https://doi.org/10.5209/ESMP.54245

Cebrián-Herreros, M. (2008) La radio en internet. De la radio web a las redes sociales y a la radio móvil. Buenos Aires: La Crujía. ISBN: 9789876010634

Cebrián-Herreros, M. (2009). Comunicación interactiva en los ciber medios. Comunicar, 17(33), 15-24. https://doi.org/10.3916/c33-2009-02-001

Cheval, J. J. (1997). Les Radios en France. Histoire, état et enjeux. Col. Médias et Nouvelles Technologies. Rennes: Apogée.

Cheval, J. J. (2003). Audiences, publics et pratiques radiophoniques, Pessac: Maison des Sciences de l'Homme d'Aquitaine.

Cheval, J. J. (2008, 23 de junio). La radio: paroles données, paroles à prendre. Médiamorphoses, pp 20-149, Paris.

Cheval, J. J. (2010). ¿L'expérience française des radios locales associatives, un modèle économique?. En Cailler, Pineu y Pradie (Ed.) La longue marche des télévisions associatives. Paris: L'Harmattan. Les Cahiers de Champs Visuels.

Gallego-Pérez, J. (2010). Podcasting: Nuevos modelos de distribución para los contenidos sonoros. Barcelona: UOC. ISBN: 9788497888578

Gallego-Pérez, J. (2012). Relaciones entre pod-casting, radio y movilidad. La distribución de contenidos de audio. Telos, 92, 127-135. https://dialnet.unirioja.es/servlet/articulo?codigo=3993912

González Conde, J. (2014) La ciberradio como modalidad interactiva de comunicación multimedia en su dimensión expresiva hipertextual e hipermedial. En Requeijo y Gaona (ed.) Contenidos innovadores en la universidad actual, pp 363-370 Madrid Mac Graw Hill Ed. 
Glevarec, H. (2012, septiembre). Radio: ouvrez grand vos oreilles! Catalogue de l'Exposition sur l'histoire de la radio organisée par le Centre National des Arts et Métiers, Février. Milan: Silvana Editorial.

Lefebvre, T. (2011) La bataille des radios libres: 1977-1981. París: Nouveau Monde Éditions.

Martínez-Costa, M. P., Moreno, E., Amoedo, A. (2012). La radio generalista en la red: un nuevo modelo para la radio tradicional. Anagramas, 10(20), 165-180. http://revistas.udem.edu.co/index.php/anagramas/article/view/614/555

Martínez-Costa, M. P., Moreno, E., Amoedo, A. (2018). Mapa de la radio online en España: tipología y caracterización en el contexto de los cibermedios. El profesional de la información, 27(4), 849-857. https://doi.org/10.3145/epi.2018.jul.14

Ortega Benito, R. (1997). Las radios internacionales y su relación con la audiencia. Tesis doctoral. Facultad de Ciencias de la Información. Madrid. Universidad Complutense.

Ortiz Sobrino, M. A. (2013). De la propaganda franquista a la Marca España: 70 años de Radio Exterior de España. Historia y Comunicación Social,18, extra1, 219-230.

Ortiz Sobrino, M. A. (2014). La radio como medio para la comunicación alternativa y la participación del Tercer Sector en España y Francia. Comunicación y hombre, 10.

Martínez Arias, S. y Martínez Arias, A. (2013). Evolución de la radio global y competencia en Internet. El caso de Radio Exterior de España. Estudios sobre el Mensaje Periodístico, 19, 487-504,1. http://dx.doi.org/10.5209/rev ESMP.2013.v19.n1.42534 .

Milito, C. y Casajús, L. (2009). La radio en internet, un breve marco teórico para la comprensión y el estudio del fenómeno. Question,1, 24.

Montes Fernández, F. J. (1998). Los orígenes de la radiodifusión exterior. Madrid. Ed. Complutense.

\section{AUTORES}

\section{Juan Carlos González Pérez}

Periodista experto en comunicación, marketing digital y creación de contenidos. Investigador por la Universidad Complutense de Madrid en el campo del periodismo, las redes sociales y la información radiofónica. A lo largo de varios años he trabajado en medios de comunicación como la Cadena SER, EI Mundo, ABC, Onda Madrid o bez.es; instituciones como Injuve, Ametic, Academia de la Televisión, España Digital o Multinacionales por Marca España y agencias como Open Ideas dando valor a las nuevas narrativas periodísticas y formas de comunicar. Investigador por la UNED y por la Universidad Complutense de Madrid en Periodismo, en áreas como el social 
media, el periodismo digital, la educación mediática, el fact checking, la comunicación y el marketing digital, la producción e información radiofónica. Miembro de los proyectos MOOC Quimica Made in Spain de la FECYT y YouCheck Project (Eco Learning). Coordinador de estudiantes en el proyecto de radio y juventud "Europa on Air" (Comisión Europea / Erasmus+ -2018-2019). En la actualidad, community manager y miembro del equipo digital de Newtral.es

Google Scholar: https://scholar.google.es/citations?hl=es\&user=EXJ4DYOAAAAJ

\section{Miguel Angel Ortiz Sobrino}

Doctor en Ciencias de la Información por la UCM. Licenciado en Periodismo y en Ciencias de la Imagen Visual y Auditiva. Es Diplomado en Investigación de Medios por A.I.M.C. PDI en el Departamento de Periodismo y Nuevos medios de la Universidad Complutense de Madrid. Vinculado a RTVE desde 1977, donde ha desempeñado, entre otros, los cargos de Jefe de Programas de Radio 5, Subdirector de Emisoras Territoriales de RNE y Subdirector de Planificación de Programas de RNE. Entre el año 2000 y 2009 ha dirigido el Instituto Oficial de Radio y Televisión. También ha sido Director Adjunto de Radio Televisión Madrid y Jefe de Programas de Onda Madrid

Orcid ID: https://orcid.org/0000-0003-0103-9524

Google Scholar: https://scholar.google.es/citations?user=30CGQs4AAAAJ\&hl=es

\section{Ana Mancho Laiglesia}

Departamento: Unidad Predepartamental de Periodismo y de Comunicación Audiovisual y Publicidad. Área: Periodismo. Centro: Facultad de Filosofía y Letras Grupo: GICID (Grupo de Investigación en Comunicación e Información Digital) UNIZAR teaching activity. Géneros y redacción periodística II. Graduado en Periodismo. During academic year 2020-21Realización audiovisual: reportaje y documental. Graduado en Periodismo. From the 2011-12 course to the 2020-21 course. Géneros informativos en tv. Graduado en Periodismo. During academic year 2019-20

Orcid ID: https://orcid.org/0000-0002-9621-1819

Google Scholar: https://scholar.google.es/citations?user= xMuVSkAAAAJ\&hl=es

\section{Jacinto Gómez López}

Doctor en Periodismo

Profesor del Departamento Periodismo y Nuevos Medios de la Universidad Complutense de Madrid

Orcid ID: https://orcid.org/0000-0002-7754-938X

Google Scholar: https://scholar.google.com/citations?user=gqG7BigAAAAJ\&hl=es 